University of Windsor

Scholarship at UWindsor

Winter 2015

\title{
Psychological Help-Seeking among Latin American Immigrants in Canada: Testing a Culturally-Expanded Model of the Theory of Reasoned Action Using Path Analysis
}

\author{
B.C.H Kuo \\ University of Windsor \\ Alma Roldan-Bau \\ Robert Lowinger
}

Follow this and additional works at: https://scholar.uwindsor.ca/psychologypub

Part of the Psychology Commons

\section{Recommended Citation \\ Kuo, B.C.H; Roldan-Bau, Alma; and Lowinger, Robert. (2015). Psychological Help-Seeking among Latin American Immigrants in Canada: Testing a Culturally-Expanded Model of the Theory of Reasoned Action Using Path Analysis. International Journal for the Advancement of Counselling. \\ https://scholar.uwindsor.ca/psychologypub/34}

This Article is brought to you for free and open access by the Department of Psychology at Scholarship at UWindsor. It has been accepted for inclusion in Psychology Publications by an authorized administrator of Scholarship at UWindsor. For more information, please contact scholarship@uwindsor.ca. 



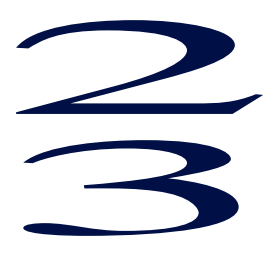




\title{
Psychological Help-Seeking among Latin American Immigrants in Canada: Testing a Culturally-Expanded Model of the Theory of Reasoned Action Using Path Analysis
}

\author{
Ben C. H. Kuo \& Alma Roldan-Bau \& Robert Lowinger
}

\# Springer Science+Business Media New York 2015

\begin{abstract}
The current study investigated the psychosocial and cultural predictors of psychological help-seeking based on the Theory of Reasoned Action (TRA: Ajzen and Fishbein 1980) in a sample of 223 adult Latin American immigrants living in Canada. Using path analysis, the results provided empirical support for the TRA, as both help-seeking attitudes and subjective norms were found to influence participants' help-seeking intentions. Moreover, the re-specified culturally-expanded model showed a good fit to the data and revealed the direct and indirect effects that bi-directional acculturation (Latino and Canadian Cultural orientations), familism, and collective coping had on help-seeking intentions. The results point to the integral roles familism and subjective norms of social referents (e.g., parents, siblings) play in the help-seeking decision process among Latin Americans. Limitations, future research directions and clinical implications are considered and discussed.
\end{abstract}

Keyword Help-seeking $\cdot$ Theory of reasoned action $\cdot$ Acculturation $\cdot$ Familism $\cdot$ Coping $\cdot$ Latino

\section{Introduction}

There has been considerable evidence and discussion concerning the underutilization of mental health services, particularly among members of racial and ethnic minority groups, in both the U.S. (Sue and Sue 2013) and Canada (Kuo et al. 2006a; Whitley et al. 2006). U.S. research has repeatedly shown that Latino Americans, Asian Americans, and African Americans are less likely to access mental health services than White Americans, despite experiencing comparable rates of mental health disorders across all groups (U.S. Department of Health and Human Services 2001). Likewise, in Canada, research has shown a greater tendency for non-European immigrants to underutilize mental health services (Whitley et al. 2006), as well as more

B. C. H. Kuo (*) : A. Roldan-Bau

Department of Psychology, University of Windsor, 401 Sunset Ave., Chrysler Hall South, Windsor, Ontario N9B 3P4, Canada

e-mail: benkuo@uwindsor.ca

R. Lowinger

Bluefield State College, Bluefield, WV, USA

Published online: 17 February 2015 
negative attitudes toward psychological help-seeking among ethnic minority university students as compared to their White/Caucasian counterparts (Kuo et al. 2006a).

Specifically, for Latin American ${ }^{1}$ immigrants living in North America, cumulative research has substantiated that this population tends to underutilize mental health services in comparison to the non-Latino White population (U.S. Department of Health and Human Services 2001). At the same time, scholars have observed that some segments of the Latin American population may be particularly vulnerable and susceptible to psychological problems and distress, such as those who have had war-related trauma and terror in their countries of origin (Prilleltensky 1993).

Currently there is little empirical data and research about Latin American populations' psychological help-seeking attitudes and intentions and the relevant factors that impact these processes. For counselling and practical purposes, it is, therefore, unclear what strategies or solutions need to be undertaken to promote better mental health and mental health service utilization for Latin American immigrants. Consequently, culturally-sensitive research on psychological treatment of Latin Americans is sorely needed to inform those who work directly or indirectly with such communities or client populations, including counsellors, psychologists, other mental health providers, agency personnel and policy makers.

Given the cultural characteristics of Latin Americans, previous literature has identified unique psychosocial and cultural factors that potentially impact on their help-seeking attitudes and beliefs. These have included such factors as gender, acculturation, familism, stigma, subjective norms, and cultural and religious coping (e.g., Chiang et al. 2004; Miville and Constantine 2006; Ramos-Sanchez and Atkinson 2009). Incorporating these important variables into the examination of help-seeking among Latin Americans is likely to enhance our understanding of ways to ensure culturally-responsive counselling and psychological interventions, removing potential barriers for services, and eventually improving mental health service utilization for this particular population.

With respect to research specifically, scholars have also made two notable methodological recommendations for improving current psychological treatment-seeking studies: a) to apply theoretical models to guide help-seeking research and research questions; and b) to use more sophisticated statistics, such as path analysis, to simultaneously examine the direct and indirect effects of multiple variables on individuals' help-seeking attitudes and behaviors (Cramer 1999; Vogel et al. 2005). There has also been limited but growing research that has incorporated critical cultural influences/factors into the examination of psychological help-seeking among ethnic minorities (e.g., Kim and Park 2009; Kuo et al. 2006a).

As such, the purpose of the present study was to examine psychological help-seeking in a community sample of adult Latin American immigrants living in Canada. Grounded in the well-established Theory of Reasoned Action (TRA: Ajzen and Fishbein 1980), the present investigation tested a culturally-expanded model of the TRA, involving the inclusion of bidirectional acculturation, familism, stigma, and cultural and religious coping variables. The TRA and the variables in the model were simultaneously examined and analyzed with the statistical procedure of path analysis. Through examining the relevance and the predictive power of these psychosocial and cultural variables in explaining help-seeking intentions among Latin immigrants in the hypothesized models, we hoped to expand the current knowledge-base on the subject and to aid counsellors and psychologists in knowing how to promote and devise more culturally-responsive and clinically-effective counselling and

\footnotetext{
${ }^{1}$ Given that BLatin American^ is the official descriptor used by Statistics Canada in collecting national census data, this term is used throughout this paper. Furthermore, the term BLatino ${ }^{\wedge}$ is used in the article as a generic term to denote both BLatino^ ${ }^{\wedge}$ and BLatina ${ }^{\wedge}$.
} 
psychological services for Latin American immigrant clients. The following sections survey the relevant literature for the study.

\section{Context and Demographics of Latin Americans in Canadian}

In 2006, Latin Americans made up $1 \%$ of Canada's total population, with a total number of 304,200 , and stood as the 5th largest visible minority group in that country (Statistics Canada 2007). In the literature the term BLatin Americans ${ }^{\wedge}$ specifically refers to individuals originating from Mexico, South and Central America, Cuba, Puerto Rico, the Dominican Republic and other groups of a Spanish cultural origin, regardless of race (Marín and Marín 1991). In the case of Canada, the majority of Latin Americans are mainly from El Salvador, Mexico, and Chile, with most of them being first-generation immigrants $(73 \%)$ who immigrated to Canada after 1980 (Lindsay 2007). Latin American immigrants in Canada have typically arrived in various migration waves, often as refugee claimants in response to political conflict, violence, and civil war in their countries of origins and, thus, many have experienced or witnessed trauma and persecution in their home countries (Riano-Alcala 2008).

\section{Theory of Reasoned Action as a Theoretical Framework for Psychological Help-Seeking}

According to the Theory of Reasoned Action (TRA; Ajzen and Fishbein 1980), and its more contemporary derivative Theory of Planned Behavior (Ajzen 1991), a person's intention to either perform or not perform a behavior is the most important factor in determining whether the person will ultimately engage in that behavior or not. Furthermore, the TRA dictates that individuals' intentions are shaped by two crucial factors: a) Battitudes ${ }^{\wedge}$ toward the given behavior, with this referring to one's evaluation or appraisal of the behavior in question, and b) perceptions of Bsubjective norms, ${ }^{\wedge}$ with this referring to social pressure or expectation to either engage or not engage in the target behavior.

Only relatively recently has the TRA been applied to mental health and psychological helpseeking research. For example, using the TRA, Vogel et al. (2005) found that several psychological variables, including social stigma and social norms, significantly predicted American college students' psychological help-seeking attitudes. Moreover, as hypothesized by the TRA, college students' help-seeking attitudes in turn, predicted their intentions to seek counseling. In yet another study involving the TRA, Vogel et al. (2007) found that American college students' self-stigma and help-seeking attitudes effectively mediated the relationship between public-stigma and help-seeking intentions. Thus, emerging evidence points to the TRA as a promising theoretical framework that can help researchers discern and conceptualize individuals' help-seeking attitudes and intentions more precisely.

\section{Subjective Norms and Help-Seeking}

Limited research has shed light on the link between subjective norms (i.e., social pressures or social group expectations) and psychological help-seeking among members of racial and ethnic groups. For instance, Kim and Park (2009) adapted the TRA model and found that stronger Asian values among Asian American college students were related to more negative subjective norms about seeking help, and negative subjective norms, in turn, were associated with less willingness to see a counselor. In a rare but important study with an outpatient sample 
of 95 Latin American adults (predominantly Mexicans) in the U.S., participants' help-seeking intentions in regard to formal help were predicted by both the subjective norms of their family and their attitudes toward mental health providers - an outcome consistent with the TRA (Cabassa and Zayas 2007).

\section{Acculturation and Help-Seeking among Latin Americans}

According to the cultural barrier theory (Leong et al. 1995), greater adherence to Latin American cultural values (i.e., cultural orientation) is predicted to interfere with psychological help-seeking among Latin American immigrants. However, applying a bi-directional measure of acculturation, Miville and Constantine (2006) found that endorsing a greater American cultural orientation among Mexican American students was positively correlated with their help-seeking behavior over the past year. In a dissertation study by Herrera (2006) using structural equation modeling, holding an American cultural orientation among Mexican college students was shown to have a significant indirect effect on their willingness to see a counselor, as it related to less shame in doing so, which, in turn, led to a greater willingness to see a counselor. Likewise, students with a stronger Mexican cultural orientation also reported less shame, which was also associated with greater willingness to see a counselor. This last study highlights the critical importance of examining the complex direct and indirect effects of predictors of psychological help-seeking simultaneously. As follows, the present study employed a bi-directional measure of acculturation and utilized path analysis to assess treatment-seeking attitudes and intentions among Latin American adults.

\section{Familism and Help-Seeking Among Latin Americans}

It has been well documented that Familismo or familism represents a central cultural value among Latin Americans (Sue and Sue 2013). Ramos-Sanchez and Atkinson (2009) found in a sample of Mexican American college students that familism was not correlated with helpseeking attitudes but, instead, was negatively correlated with help-seeking intentions. However, due to the weak internal consistency of the familism scale reported in the study, confidence in these results was problematic. In another study, Miville and Constantine (2006) found that among Mexican American students, greater perceived family support was associated with more negative attitudes toward seeking help. Lastly, a dissertation study by Garcia (2008) showed that Puerto Rican and Dominican college students who valued parental honor were less able to tolerate stigma and, thus, held more negative treatment-seeking attitudes. In view of the limited empirical work in this area, the present study further attempted to closely assess and test the role of familism in help-seeking by using a multidimensional measure.

\section{Cultural and Religious Coping and Help-Seeking among Latin Americans}

Recently, there has been increasing empirical and conceptual advances pointing to cultural diversity in coping behaviors and patterns among culturally diverse groups and individuals (Kuo 2011; Kuo et al. 2006b), including coping in the form of help-seeking behaviors in response to psychological and emotional problems (e.g., Chiang et al. 2004; Moore and Constantine 2005). For instance, in one study it was shown that both African American and Latino/Latina American college students expressed unfavorable attitudes toward counseling, 
and both groups preferred coping that involved informal help from family, friends, and significant others (Chiang et al. 2004). In a similar vein, Constantine et al. (2003) found that among Latino American and African American students, higher satisfaction with one's social supports actually predicted less willingness to seek counseling for mental health problems. The tendency to cope with stress and psychological distress by resorting to family and interpersonal social support has been incorporated into the measurement of a cultural coping strategy of 'collective coping', as defined and described in recent cross-cultural coping research (Kuo 2011; Moore and Constantine 2005), and was also measured and examined in the present research.

Religion/spirituality and religious coping have also been found to play a central role in Latin American help-seeking (Altarriba and Bauer 1998). Some researchers have suggested that Latin Americans who identify themselves as more religious and who use religious coping may be more willing to seek help from religious leaders than from formal psychological providers (Altarriba and Bauer 1998). Likewise, among Latin American women those who endorsed more strongly religious or supernatural reasons for causes of mental illness were found to be less willing to utilize mental health services (Alvidrez 1999). Given the suggested significance of religion and spirituality in the life of Latin Americans, religious coping items were created and assessed in the present research, in addition to the use of an empirically validated measure of cultural coping.

\section{Gender, Previous Mental Health Service Experience and Help-Seeking}

The role of gender in psychological help-seeking has not been well studied in Latino populations. However, a variety of help-seeking studies with other populations suggest that women are significantly more favorably inclined to seek psychological help for emotional distress. Kuo et al. (2006a) utilized an ethnically diverse sample of Canadian university students and found that the female participants had more positive attitudes toward seeking professional psychological help than their male counterparts. In a sample of American college students in the U.S., Lowinger (2012) also found that women were significantly more willing to get help for an alcohol problem than were men.

Existing research has also suggested that previous service use is a positive predictor of psychological help-seeking. For instance, Masuda et al. (2012) found that among African American college students, past help-seeking experience was associated with having more positive help-seeking attitudes and with lower mental health stigma. Given these findings, Latin American immigrant participants' gender and previous counseling experience were controlled as covariates in the current study.

\section{The Current Study}

The present study addressed the following two research questions in a community sample of adult Latin American immigrants in Canada:

Research Question 1 To what extent does the TRA help explain psychological help-seeking intentions among Latin Americans in Canada?

Research Question 2 To what extent does the inclusion of relevant psychosocial and cultural variables help improve the TRA's ability to explain help-seeking intentions among Latin Americans in Canada? 
To these ends, the study was designed to: a) test the TRA model of help-seeking; b) examine a culturally-expanded TRA model of help-seeking that included variables of stigma, Latino and Canadian cultural orientations, familism, and cultural and religious coping. Potential moderators of treatment-seeking, including gender, previous counseling experience, and psychological distress, were also entered as covariates in predicting help-seeking intentions in the latter model.

\section{Hypotheses}

First, with respect to the testing of the TRA, it was hypothesized that help-seeking attitudes and subjective norms would be positively related to help-seeking intentions, as predicted by the theory (Ajzen and Fishbein 1980). For the culturally-expanded TRA model, we hypothesized the following relationships. Building on Vogel et al.'s (2007) study, it was posited that higher stigma would be negatively related to attitudes, subjective norms, and intentions. Furthermore, help-seeking attitudes and subjective norms were also hypothesized to mediate the effect of stigma on intentions.

In terms of the culturally-expanded TRA model, the hypothesized relationships among the help-seeking and cultural variables in the model were supported by previous help-seeking research studies with other ethnic minority groups (cf., Kim and Omizo 2003). On the basis of the cultural barrier theory (cf., Leong et al. 1995), we hypothesized that both familism and Latino cultural orientation would be negatively related to help-seeking attitudes, subjective norms, and help-seeking intentions, whereas a Canadian cultural orientation would be positively related to these three variables. This was based on the cultural barrier theory (Leong et al. 1995), which suggests that more traditional cultural values are typically antithetical to Western psychological interventions.

It was further predicted that Latin American cultural coping behaviors, including collective coping and religious coping, would be negatively associated with help-seeking attitudes, subjective norms, and help-seeking intentions. This prediction was based on previous findings that Latin Americans who cope through and seek help from their in-group and religious communities were less willing to seek formal psychological intervention (Alvidrez 1999; Altarriba and Bauer 1998). Consistent with the TRA model, it was hypothesized that attitudes and subjective norms would mediate the effect of cultural variables (i.e., familism, acculturation and coping) on intentions, and that these variables would improve the fit of the TRA model. Finally, given that previous research has found that women (Kuo et al. 2006a; Lowinger 2012), individuals who have previously sought psychological treatment (Alvidrez 1999; Masuda et al. 2012), and those experiencing greater psychological distress (Cramer 1999) were more likely to seek psychological help, it was further posited that gender, previous counseling experience, and psychological distress would each moderate the effect of the predictors on help-seeking intentions in the culturally-expanded TRA model.

\section{Methods}

\section{Participants}

A total of 223 Latin American adults (63.7 \% females, $36.3 \%$ males), with a mean age of 46.19 $(\mathrm{SD}=15.17)$ and ranging from 18 to 78 years old participated in the study. Nearly $70 \%(\mathrm{~N}=155)$ of the participants chose to complete the questionnaire in a paper-and-pencil format and the rest $(\mathrm{N}=$ 68) completed the same questionnaire in an online format. The sample was comprised of mostly foreign-born individuals (88.8 \%) holding Canadian citizenship (78.5\%) from 15 different Latin 
American countries. A total of $72.2 \%$ of the sample reported to be 1st-generation immigrants (born outside of Canada and immigrated to Canada after the age of 12), $15.2 \%$ identified as 1.5-generation immigrants (born outside of Canada and immigrated to Canada before the age of 12), and $10.8 \%$ identified as 2nd-generation status (born in Canada). Most participants identified as Catholic (61\%) or non-Catholic Christian (27.8\%) religions. A total of $61 \%$ of the participants reported having completed a 2-year college degree or a university degree. Finally, only $32.7 \%$ of the sample reported having sought prior mental health services.

\section{Procedure}

A multi-pronged approach, as suggested by researchers working with immigrant and ethnic populations in Canada (Kuo et al. 2008), was adopted in this study to recruit Latin American participants. The recruitment methods included: a) contacting the leaders of various Latin American cultural and religious organizations in Toronto and across Canada; b) directly recruiting members of these organizations in person (undertaken by the second author, who is a Latin American immigrant herself); c) e-mailing personal contacts (also of the second author) about the study; d) using the Bsnowball^ ${ }^{\wedge}$ technique by asking participants to share the study's information with their significant others and friends; and e) disseminating the information about the study through emails and social media sites (e.g., Facebook). The research was approved by the Research Ethics Board at the university where the study occurred and was conducted in accordance with APA ethical standards. Participants read a letter of information and signed a consent form before starting the survey. As an incentive, all participants were given the option to enter into a draw for one iPod Nano and four \$25 gift certificates for Walmart.

\section{Measures}

To address potential language issues with completing the survey, two equivalent versions of the questionnaire, one in English and the other in Spanish, were made available to the participants and were prepared based on the back-translation procedure recommended by Brislin (1986). Most of the measures in the survey, except for two (the ARSMA-II and the Attitudinal Familism Scale) for which Spanish versions are available, were carefully translated from English to Spanish by the second author, who is a native Spanish speaker, and two additional bilingual translators. Special care was taken to remove region-specific phrases and terminologies to ensure that the measures could be understood by participants from Central American as well as South American countries. Of the participants, $65.9 \%$ opted to complete the Spanish version of the questionnaire and $34.1 \%$ completed the English version. In addition to demographic questions, the following 8 measures were included in the questionnaire.

\section{Attitudes Toward Seeking Professional Psychological Help-Short Form}

(ATSPPH-SF: Fischer and Farina 1995). The ATSPPH-SF is a 10-item measure to assess individuals' attitudes toward seeking professional help for psychological problems. A sample item is BIf I were experiencing a serious emotional crisis at this point in my life, I would be confident that I could find relief in psychotherapy.^ The scale is scored on a 4-point Likert scale. The ATSPPH-SF has been used in previous help-seeking research with diverse ethnic minority students in Canada (cf., Kuo et al. 2006a) and with Latin American participants in the U.S. (cf., Miville and Constantine 2006), with acceptable psychometric properties. In the current study, the 
internal consistency for the scale was adequate for the English version $(\alpha=0.77)$, the Spanish version $(\alpha=0.68)$, and the overall combination of the two $(\alpha=0.72)$.

\section{Subjective Norms Assessment}

In the present research, subjective norms in regards to participants' important referents were assessed using six items created by the authors, based on the recommendation of Ajzen and Fishbein (1980) and on previous research with Latin Americans using a similar method (cf., Cabassa and Zayas 2007). Following the authors' review of the literature pertaining to Latino populations, the following referents were identified and included in this subjective norms measure: significant other/spouse, immediate family, extended family, friends, and important others in his/her life. As an example, one of the subjective norm items read: BMy immediate family (parents and siblings) think I should seek help from a professional counselor if I were experiencing a persistent personal problem in my life. ${ }^{\wedge}$

Subjective norms were scored on a 7-point Likert scale and calculated by summing participants' responses across the different referent groups. The internal consistency of the subjective norms scale in the current study was very good for the English version $(\alpha=0.93)$, the Spanish version $(\alpha=0.95)$, and the overall combined version $(\alpha=0.94)$.

\section{Intentions to Seek Counseling Inventory}

(ISCI: Robertson and Fitzgerald 1992). The 15-item ISCI assesses personal problems that are commonly referred to as reasons for seeking professional psychological services, such as relationship difficulties, depression, and loneliness. For each problem, respondents rate the likelihood of seeking help through professional services on a 6-point Likert scale. In the current investigation, the items involving academic concerns were removed, and the word Bparents' on the relevant items was changed to $B f a m i l y \wedge$ to better reflect the non-student, adult characteristics of the present sample. The ISCI yielded very good internal consistency for the English version $(\alpha=0.93)$, Spanish version $(\alpha=0.94)$, and the overall combined version $(\alpha=0.94)$ in the study.

\section{Perceptions of Stigmatization by Others for Seeking Help}

(PSOSH: Vogel et al. 2009). The 5-item PSOSH is a recently developed measure of an individual's perception of stigma in his or her social network and is scored on a 5-point Likert scale. The test instruction reads: BImagine that you had a problem that needed to be treated by a mental health professional. If you sought mental health services, to what degree do you believe that the people you interact with would ____..$^{\wedge}$ Sample items include Breact negatively to you ${ }^{\wedge}$ and Bthink you posed a risk to others. ${ }^{\wedge}$ The PSOSH was reported to have good internal consistencies and adequate testretest reliability across four samples (Vogel et al. 2009). The test developers further reported adequate psychometric properties of the instrument when used with racial and ethnic minority samples in the U.S. In the present study the internal consistency of the PSOSH was very good for the English version ( $\alpha=0.91)$, Spanish version $(\alpha=0.93)$, and the overall combined version $(\alpha=0.92)$.

\section{Acculturation Rating Scale for Mexican Americans-II}

(ARSMA-II: Cuéllar et al. 1995). The ARSMA-II is a 30-item bi-directional measure of acculturation, with 17 items for Mexican cultural orientation and 13 items for American cultural orientation. Items in this scale are scored on a 5-point Likert scale, with examples of items including, BMy friends are of Anglo origin, ${ }^{\wedge}$ and BMy friends are of Mexican origin. ${ }^{\wedge}$ 
In the present study the term BAnglo ${ }^{\wedge}$ was changed to BEuropean Canadian ${ }^{\wedge}$ and the term BMexican $^{\wedge}$ was changed to BLatino(a)/Hispanic ${ }^{\wedge}$ in the scale items to better reflect the Canadian context of the study and its participants. Hence, the corresponding outcomes are referred to as BCanadian Cultural Orientation^ ${ }^{\wedge}(\mathrm{CCO})$ and BLatino Cultural Orientation ${ }^{\wedge}$ (LCO). In the present study, the ARSMA-II demonstrated good internal consistency for the English version (LCO $\alpha=0.86$ and $\operatorname{CCO} \alpha=0.80$ ), Spanish version ( $\operatorname{LCO} \alpha=0.83$ and $\operatorname{CCO} \alpha=0.84$ ), and the overall combined version ( $\mathrm{LCO} \alpha=0.85$ and $\operatorname{CCO} \alpha=0.84)$.

\section{Cross-Cultural Coping Scale}

(CCCS: Kuo et al. 2006b). The CCCS is a 26-item, scenario-based coping measure designed to assess both individualistic and collectivistic coping strategies, with three subscales: Collective coping (CC: e.g., BI take the course of action that is most acceptable to my family^), Engagement coping (EC; e.g., BI put extra effort or work extra hard to resolve the problem ${ }^{\wedge}$ ), and Avoidance coping (AC: e.g., BI try to block out or forget about what's bothering $\mathrm{me}^{\wedge}$ ). Participants are asked to imagine being in a hypothetical stressful scenario based on dealing with symptoms associated with depression and then using a 6-point Likert scale to rate the likelihood of using various methods of coping in responding to the described situation. Minor modifications, including changing the word Bparents ${ }^{\wedge}$ to Bfamily^ and BChinese values ${ }^{\wedge}$ to BLatino values ${ }^{\wedge}$, were made on the relevant items on the scale.

Additionally, four extra items involving religious coping (RC) were generated and added to the assessment of coping, based on the researchers' review of Latin American coping literature (e.g., Abraído-Lanza et al. 2004). They included: a) BI put my trust in $\mathrm{God}^{\wedge}$; b) BI seek God's help $^{\wedge}$; c) BI try to find comfort in my religion ${ }^{\wedge}$; and d) BI seek advice or help from my religious leader. ${ }^{\wedge}$ The present study obtained adequate to good internal consistency for the coping items for the English version (CC $\alpha=0.75$, EC $\alpha=0.73, \mathrm{AC} \alpha=0.76, \mathrm{RC} \alpha=0.90$ ), the Spanish version (CC $\alpha=0.71, \mathrm{EC} \alpha=0.77, \mathrm{AC} \alpha=0.70, \mathrm{RC} \alpha=0.80)$, and the overall combined version ( $\mathrm{CC} \alpha=0.73, \mathrm{EC} \alpha=0.76, \mathrm{AC} \alpha=0.71, \mathrm{RC} \alpha=0.85)$.

\section{Attitudinal Familism Scale}

(AFS: Steidel and Contreras 2003). The 18-item AFS is a multidimensional scale to measure Latin American familism, with 4 subscales: a) Subjugation of Self to the Family; b) Familial Interconnectedness; c) Familial Support; and d) Familial Honor. Example items for the scale include: BA person should rely on his or her family if the need arises ${ }^{\wedge}$ and BA person should feel ashamed if something he or she does dishonors the family. ${ }^{\wedge}$ The scale is scored on a 10-point Likert scale and an overall familism score was computed by calculating a mean score across the subscales.

In the original instrument development study, involving a sample consisting of participants with mostly a Puerto Rican background, Steidel and Contreras (2003) reported adequate reliability for the overall scale and its subscales and support for the scale's convergent and divergent validity with a measure of acculturation. In the present investigation, the familism scale demonstrated good internal consistency for the English version $(\alpha=0.86)$, the Spanish version $(\alpha=0.82)$, and the overall combined version $(\alpha=0.84)$.

\section{Brief Symptom Inventory-18}

(BSI-18; Derogatis 2000). The BSI-18 asks participants to rate their degree of distress over the past week regarding a range of symptoms on a 5-point Likert scale. It is comprised of three dimensions: Somatization (SOM), Depression (DEP), and Anxiety (ANX), each with six items. In the present study the Global Severity Index (GSI) was used in the analyses 
and the measure showed very good internal consistency for the English version $(\alpha=0.92)$, Spanish version $(\alpha=0.93)$, and the overall combined version $(\alpha=0.93)$.

Results

To address research question \#1 about the applicability of the TRA in explaining help-seeking intentions among Latin Americans, a stand-alone TRA model as originally hypothesized by Ajzen and Fishbein (1980) was first tested in the analysis. This was followed by additional path analyses to address research question \#2 concerning the usefulness and the fit of the culturally-expanded help-seeking model, based on the TRA with the inclusion of critical psychosocial and cultural variables. The correlations among the key variables examined in the current study and the means and standard deviations of these variables are presented in Table 1.

Fit indices recommended by Byrne (2010) and Kline (2005) were adopted to evaluate the goodness of fit of the additive model with the current sample data. Modification indices (MI) and standardized residuals were used to detect model misspecification and to serve as guides to modify models, adhering to Byrne's (2010) recommendations. On these bases, two path models were hypothesized and tested: a) the original TRA model, and b) a culturally-expanded TRA model with distinctive psychosocial and cultural variables. Then a final re-specified model was generated post-hoc. Table 2 presents the fit indices for these various models. The description, analysis and result for each of these measurement models are described below.

Hypothesized TRA Model 1 Following research question \#1, the first hypothesized model tested the relationships among help-seeking attitudes, subjective norms and help-seeking intentions as originally posited under TRA by Ajzen and Fishbein (1980) (see Fig. 1).

Consistent with the prediction by the TRA, the results showed that attitudes and subjective norms significantly and positively correlated with intentions. The chi-square fit index was $\mathrm{X}^{2}(1)=12.62, \mathrm{p}<.001$, pointing to an inadequate fit of the model.

According to Byrne (2010), however, these results were not completely unexpected because of this test's sensitivity to large sample size, as was the case in the present sample. While the GFI value of .96 indicated a good fit, the other fit indices pointed to a poor model fit: $\mathrm{CFI}=$ 0.56 , RMSEA $=.23$, and $\mathrm{SRMR}=0.10$. In addition, the squared multiple correlation for helpseeking intentions was low $\mathrm{R}^{2}=0.06$, suggesting that the variance accounted for by this model was limited. The modification indices and the standardized residuals were also examined following Byrne's (2010) recommendations. However, these attempts did not lead to improvement of the model fit.

Hypothesized Culturally-Expanded TRA Model 2 We then proceeded to examine research question \#2 by testing and exploring whether the inclusion of critical psychosocial and cultural variables would improve the TRA model in explaining help-seeking intentions among Latin American immigrants (see Fig. 2). Thus, the culturally-expanded TRA model included stigma, familism, bi-directional acculturation, cultural and religious coping as predictors, and gender, previous use of mental health services, and psychological distress as the covariates.

The path analysis results of this model showed that the model did increase the explanatory power for help-seeking intentions from $\mathrm{R}^{2}=0.06$ for the original TRA model (Model 1) to $\mathrm{R}^{2}=$ 0.16 for the present model - a moderate increase. Despite that, this expanded TRA model was shown to have a poor overall fit to the data $\left[X^{2}(91)=469.41, \mathrm{p}<.001, \mathrm{GFI}=.79, \mathrm{CFI}=.18\right.$, RMSEA $=.15$, and SRMR=.15]. Furthermore, with the exception of Latino Cultural 
Table 1 Correlations among model variables, means, and standard deviations

\begin{tabular}{|c|c|c|c|c|c|c|c|c|c|c|c|c|c|c|c|c|c|}
\hline Variable & 1 & 2 & 3 & 4 & 5 & 6 & 7 & 8 & 9 & 10 & 11 & 12 & 13 & 14 & 15 & M & SD \\
\hline 1. ATT & - & $0.26 * *$ & $-0.21 * *$ & -0.04 & $0.14^{*}$ & -0.03 & -0.13 & -0.08 & -0.09 & -0.02 & -0.01 & $0.21 * *$ & 0.11 & $-0.27 * *$ & 0.10 & 1.93 & 0.54 \\
\hline 2. $\mathrm{SN}$ & & - & .01 & 0.12 & $-0.28 * *$ & $0.14^{*}$ & $-0.01 *$ & 0.02 & -0.04 & 0.11 & 0.04 & $0.22 * *$ & $0.14^{*}$ & $-0.19 * *$ & -0.12 & 27.92 & 11.88 \\
\hline 3. FAM & & & - & $0.15^{*}$ & -0.13 & $0.42 * *$ & 0.08 & $0.20 * *$ & $0.31 * *$ & -0.01 & 0.10 & -0.01 & -0.07 & 0.06 & -0.07 & 7.10 & 1.31 \\
\hline 4. LCO & & & & - & $-0.25 * *$ & $0.39 * *$ & 0.12 & 0.12 & $0.32 * *$ & 0.02 & $-0.15^{*}$ & $0.14^{*}$ & -0.01 & 0.08 & 0.10 & 4.02 & 0.66 \\
\hline 5. $\mathrm{CCO}$ & & & & & - & $-0.17 *$ & 0.10 & -0.06 & $-0.19 * *$ & -0.05 & 0.06 & 0.06 & -0.03 & -0.11 & 0.08 & 3.28 & 0.77 \\
\hline 6. $\mathrm{CC}$ & & & & & & - & $0.29 * *$ & $0.35^{* * *}$ & $0.40 * *$ & 0.12 & -0.01 & 0.00 & 0.04 & 0.08 & 0.09 & 21.69 & 7.32 \\
\hline 7. EC & & & & & & & - & 0.30 ** & 0.02 & -0.03 & 0.07 & -0.06 & $-0.14^{*}$ & $0.14^{*}$ & 0.10 & 28.24 & 6.00 \\
\hline 8. $\mathrm{AC}$ & & & & & & & & - & 0.11 & 0.10 & $0.18^{* *}$ & 0.01 & $0.22 * *$ & 0.01 & -0.01 & 20.47 & 7.91 \\
\hline 9. $\mathrm{RC}$ & & & & & & & & & - & 0.01 & -0.02 & -0.03 & -0.01 & 0.06 & 0.11 & 11.28 & 6.10 \\
\hline 10. $\mathrm{PB}$ & & & & & & & & & & - & $0.31 * *$ & $0.29 * *$ & $0.16^{*}$ & -0.09 & 0.09 & 13.53 & 5.47 \\
\hline 11. Stigma & & & & & & & & & & & - & 0.04 & 0.13 & -0.01 & -0.04 & 2.79 & 0.71 \\
\hline 12. ISCI & & & & & & & & & & & & - & $0.23 * *$ & $-0.24 * *$ & $0.14 *$ & 49.28 & 20.88 \\
\hline 13. BSI & & & & & & & & & & & & & - & $-.40 * *$ & 0.11 & 3.16 & 1.80 \\
\hline 14. PMH & & & & & & & & & & & & & & - & -0.11 & 1.67 & 0.47 \\
\hline 15. Gender & & & & & & & & & & & & & & & - & $\mathrm{n} / \mathrm{a}$ & $\mathrm{n} / \mathrm{a}$ \\
\hline
\end{tabular}

ATT Attitudes toward seeking professional psychological help, SN Subjective norms, FAM Familism, LCO Latino Cultural Orientation, CCO Canadian Cultural Orientation, CC

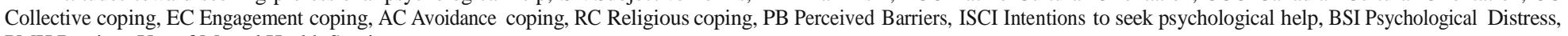
PMH Previous Use of Mental Health Services

$* \mathrm{p}<.05, * * \mathrm{p}<.01$ 
Table 2 Fit indices of study models

\begin{tabular}{lrrrrrrr}
\hline & \multicolumn{1}{c}{$\mathrm{X}^{2}$} & $\mathrm{df}$ & $\mathrm{p}$ & GFI & CFI & RMSEA & SRMR \\
\hline TRA Model 1 & 12.62 & 1 & $<.001$ & .96 & .56 & $0.23[.13, .35]$ & .10 \\
Expanded Model 2 & 469.41 & 91 & $<.001$ & .79 & .18 & $0.15[.14, .17]$ & .13 \\
Re-specified Model 3 & 55.93 & 30 & $<.001$ & .95 & .89 & $0.06[.04, .08]$ & .08 \\
\hline
\end{tabular}

TRA Model 1=Original Theory of Reasoned Action model; Expanded Model 2=Culturally-Expanded TRA Model with 3 additional covariates; Re-specified Model 3=Post-hoc final model; RMSEA values in brackets represent $90 \%$ confidence intervals. $X^{2}=$ chi-square statistic, with degrees of freedom and $p$-value; GFI= goodness-of-fit index; $\mathrm{CFI}=$ comparative fit index; RMSEA = root-mean-square error of approximation; and $\mathrm{SRMR}=$ standardized root-mean-square residual

Orientation and Psychological Distress, none of the other added psychosocial and cultural variables and covariates hypothesized in this model directly predicted help-seeking intentions.

Re-specified Culturally-Expanded TRA Model 3 Given the poor fit of the foregoing path models, a post-hoc procedure for model re-specification was undertaken. Scholars have asserted that the use of this approach to modify a model is justifiable so long as the modifications make theoretical and conceptual sense (Byrne 2010; Garson 2012). To do so, we adhered to Byrne's (2010) recommendations; specifically, the MIs (i.e., drop in $X^{2}$ or fit improvement) and standardized residuals were used as guides to pinpoint areas of model misspecification. At the same time, non-significant pathways were also removed to help improve the model fit. Garson (2012) stipulates that the rule for MIs is to add the parameter with the largest MI and then to observe the impact of such a change on model fit. Furthermore, standardized residuals represent the difference between the observed residuals and the expected residuals if the model fit were perfect (Byrne 2010). Values greater than 2.58 are considered large (Jöreskog and Sörbom 1993). Non-significant paths would be trimmed one at a time and the model fit would be re-tested after each step (Garson 2012).

Analysis of the MIs and standardized residuals resulted in various new pathways. Covariances between collective coping and familism, collective coping and Latino cultural orientation, collective coping and religious coping, and between Latino cultural orientation and religious coping were added. These pathways find theoretical and empirical support in the literature, as individuals who engage in collective coping have been found to adhere to more traditional cultural values (Kuo 2011) and religious affiliation and practices (Kuo et al. 2013). Similarly, a relation between religious coping and Latino cultural orientation also

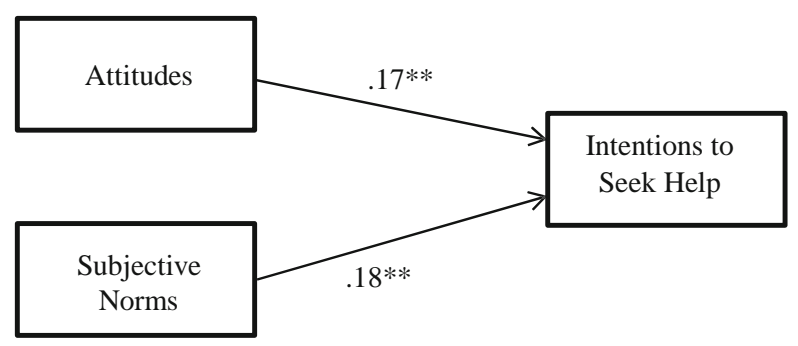

Fig. 1 The Original TRA Model 1 of Help-Seeking. Note. Standardized path coefficients are show. ** p<.01 


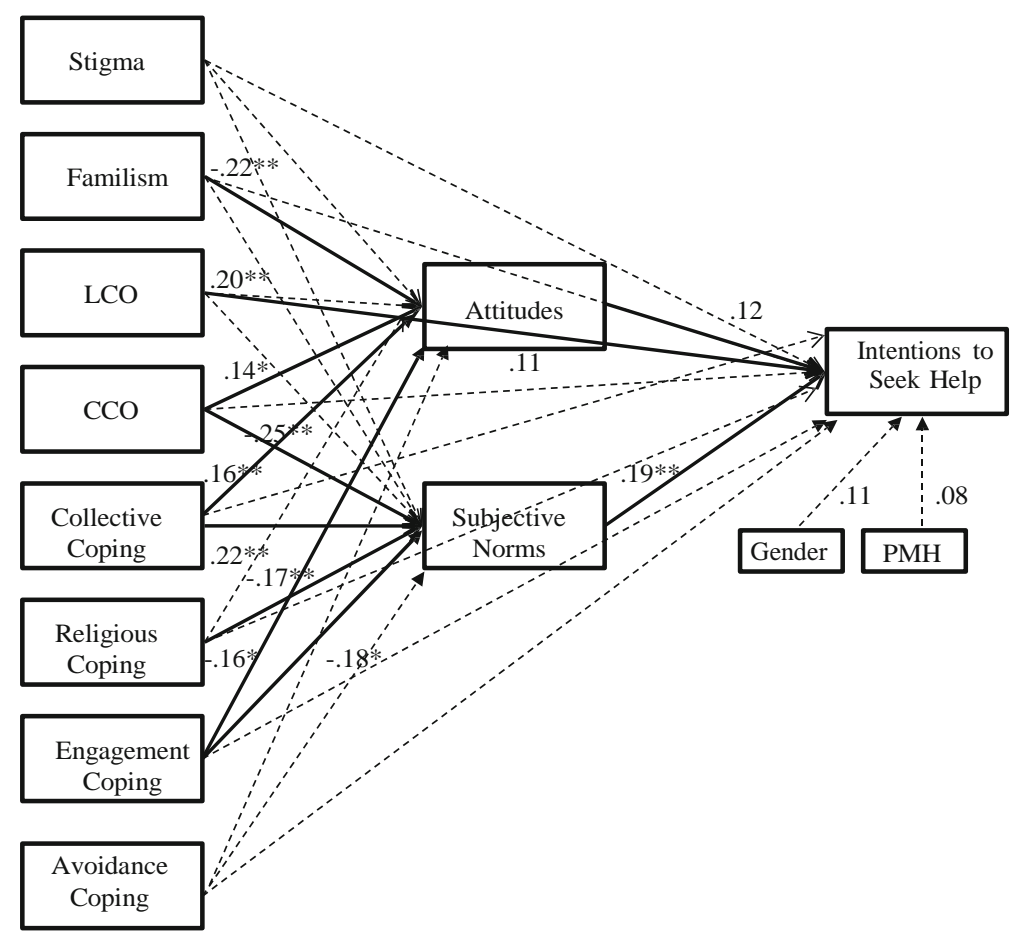

Fig. 2 Culturally-Expanded TRA Model 2 of Help-Seeking. Note. Standardized path coefficients are shown. $\mathrm{LCO}=$ Latino Cultural Orientation, $\mathrm{CCO}=$ Canadian Cultural Orientation, $\mathrm{PMH}=$ previous use of mental health services, and BSI $=$ psychological distress. $* \mathrm{p}<.05$ and $* * \mathrm{p}<.01$

made conceptual sense (Abraído-Lanza et al. 2004). Likewise, it is probable to consider that previous experience with the use of mental health services would likely affect an individual's help-seeking attitudes and subjective norms (Alvidrez 1999; Masuda et al. 2012), and would be related to their level of psychological distress (Cramer 1999). Thus, a covariance pathway was added between previous use of mental health services and psychological distress, and the pathways from previous use of mental health services to subjective norms and to attitudes were also added. Finally, in view of Ajzen and Fishbein's (1980) original TRA model, a pathway was added from attitudes to subjective norms. Subsequently, all nonsignificant pathways were removed and stigma, avoidance coping, engagement coping, and religious coping were removed from the model. This gave rise to the final respecified Model 3 (see Fig. 3).

With the modifications indicated above, the model was re-run. The fit indices for this respecified model pointed to a good fit with the data, $X^{2}(30)=55.93, p<.001$, GFI $=.95$, $\mathrm{CFI}=.89$, RMSEA $=.06$, and $\mathrm{SRMR}=.08$ and explained $15 \%$ of the variance in helpseeking intentions in the current sample (see Table 2).

\section{Discussion}

The present study set out to investigate psychological help-seeking among Latin American immigrants living in Canada by testing the original TRA model as well as a culturally- 


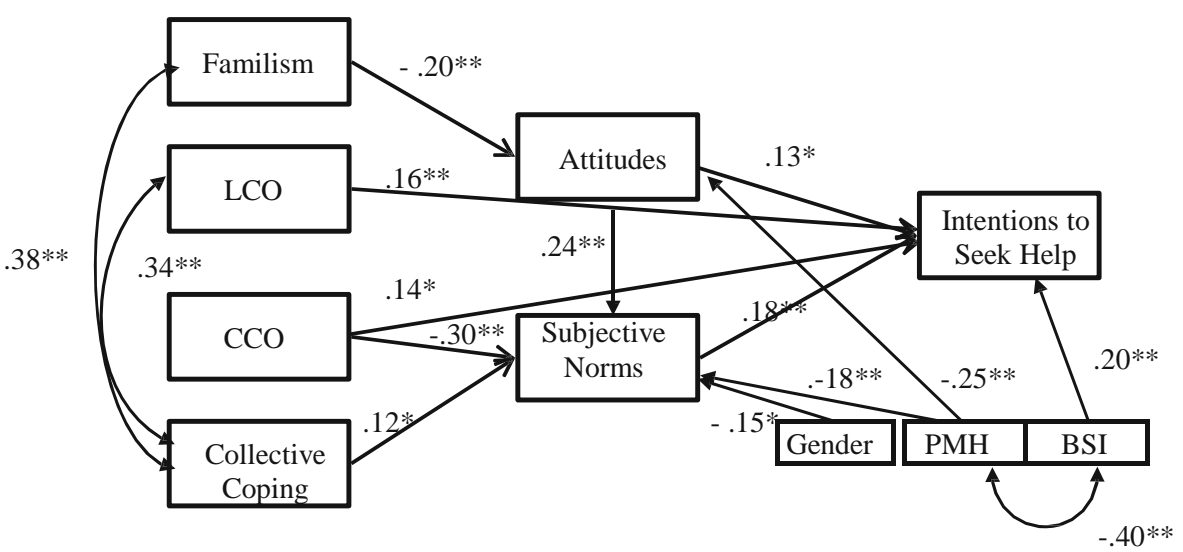

Fig. 3 Re-specified Culturally-Expanded TRA Model 3 of Help-Seeking. Note. Standardized path coefficients are shown. $\mathrm{LCO}=$ Latino Cultural Orientation, $\mathrm{CCO}=$ Canadian Cultural Orientation, $\mathrm{PMH}=$ previous use of mental health services, and BSI $=$ psychological distress. ${ }^{*} \mathrm{p}<.05$ and $* * \mathrm{p}<.01$

expanded TRA model. A number of notable findings emerged from this study. First, with respect to Research Question \#1, the results of the study provided evidence in support of the original TRA model. That is, more positive help-seeking attitudes and subjective norms were found to be related to greater help-seeking intentions in the current Latin American sample. In fact, it was shown that subjective norms were more strongly correlated with help-seeking intentions than attitudes in both the original TRA Model 1 and the re-specified Model 3.

Under Research Question \#2, the investigation sought to expand the original TRA model by incorporating cultural variables relevant to Latin Americans. Interestingly, the post-hoc respecified culturally-expanded Model (see Fig. 3) showed that help-seeking attitudes also indirectly affected help-seeking intentions through subjective norms. That is, more positive attitudes were associated with more positive perceived subjective norms, which, in turn, were associated with greater intentions to seek help. The presence of subjective norms as a significant mediator in this indirect pathway highlights the important influences of key social referents (i.e., family, parents, siblings) for Latin Americans; these social referents serve as a critical part of the mechanism in determining help-seeking decisions and intentions. These results are significant and lend additional support to the previous literature that highlights the strong collectivism, interdependence and familism among Latin Americans (Cabassa and Zayas 2007)

With respect to acculturation, contrary to the study's hypothesis, higher Latino cultural orientation among the participants was actually associated with greater help-seeking intentions, but was not associated with either help-seeking attitudes or subjective norms. While these results are not in line with Leong et al.'s (1995) earlier cultural barrier theory, they are, however, consistent with a more recent study by Ramos-Sanchez and Atkinson (2009) involving Latin American outpatients. One possible explanation is that Latin Americans with stronger Latino cultural orientation might hold more favorable help-seeking attitudes out of respect for the role of therapist who is likely to be considered to be an authority figure. However, this explanation is only speculative and would require further verification.

On the other hand, as hypothesized, Canadian cultural orientation assumed by Latin American participants in the present study was found to be positively associated with helpseeking intentions. However, contrary to the hypothesis, their Canadian cultural orientation was shown to be negatively associated with subjective norms but was not associated with 
attitudes. A closer look at the direct and indirect effects of participants' Canadian cultural orientation on intentions showed that subjective norms were a mediator in this relationship. Specifically, a greater Canadian cultural orientation was associated with greater help-seeking intentions, but a greater Canadian cultural orientation was also associated with more negative perceived subjective norms, which, in turn, were associated with lower help-seeking intentions. Given the competing effects among these paths, it is speculated that the net effect of participants' Canadian cultural orientation on intentions might be quite minimal.

Cumulative help-seeking research in this area has typically explored only the direct effects of acculturation on either help-seeking attitudes or intentions (e.g., Miville and Constantine 2006; Ramos-Sanchez and Atkinson 2009). From this vantage point, the current research is somewhat unique in that it also assessed the indirect effect of potential mediating variables between acculturation and help-seeking outcome variables through path analysis. Hence, the present results suggest that the effects of bi-directional acculturation on help-seeking might be more complex than previously conceived.

As predicted in this study, higher levels of familism among Latin Americans were associated with more negative help-seeking attitudes - an observation that finds support in previous research (e.g., Garcia 2008; Miville and Constantine 2006). The present results also demonstrated that familism had an indirect effect on intentions via attitudes (see Fig. 3). It is plausible that individuals in the present study with stronger familism might consider help-seeking from mental health services unnecessary because they perceived their families to be sufficiently supportive in meeting their needs (Miville and Constantine 2006). Alternatively, these individuals might have held more negative help-seeking attitudes because they placed greater value on family privacy and greater trust in family members than in mental health services (Alvidrez 1999). As a result, these family-centered cultural values may act to protect Latin Americans against emotional and psychological problems, but at the same time may prevent them from seeking much-needed professional help.

The effects of various cultural and religious coping strategies on help-seeking were also explored in the culturally-expanded model. In the final model, engagement coping, avoidance coping and religious coping were not found to significantly relate to psychological helpseeking. It is possible that Latin Americans who use more engagement coping behaviors may be intrinsically more independent and self-reliant when dealing with personal stress, with this perhaps rendering seeking psychological help from professionals irrelevant to these individuals. In addition, as part of their avoidant mental schema, individuals who regularly use avoidance coping might not have sufficient motivation to want to seek psychological help from professionals, with this possibly explaining the absence of significant association between avoidance coping and help-seeking. With respect to religious coping, it is plausible that Latin American participants who reported higher levels of religious coping were more religious in general, engaged in more organized religious activities, and tended to perceive greater negative subjective norms relating to help-seeking within their religious communities.

Despite the above, the apparent communal/collectivistic characteristics of the present Latin American sample seemed particularly salient, as evident in the relationship between collective coping and help-seeking in the final model. Counter to the hypothesis, collective coping was found to be indirectly positively associated with help-seeking attitudes through positive subjective norms. Nevertheless, these findings are consistent with Moore and Constantine's (2005) study, which showed that collective coping, as assessed by social support seeking, was positively correlated with attitudes toward help-seeking among Mexican American students.

Also, the two Latin American cultural variables of familism and Latino cultural orientation were found to co-vary with collective coping. That is, those who endorsed familism and Latino cultural orientation more strongly were also more likely to engage in collective coping 
strategies when dealing with their mental distress problems. Those who utilized more collective coping also tended to hold more positive attitudes and subjective norms about helpseeking, and these factors in turn influenced their help-seeking intentions.

Lastly, among the three covariates of help-seeking, only psychological distress was shown to be associated with greater intentions to seek help (see Fig. 3); an outcome consistent with the hypothesis. Moreover, it was shown that women in the study reported more negative subjective norms than did men (Kuo et al. 2006a) and that previous utilization of mental health services was associated with more favorable help-seeking attitudes as predicted (Alvidrez 1999). Curiously, the present study's attempt to include stigma into the path model did not turn out as expected. Stigma was not found to significantly relate to attitudes, subjective norms or intentions. It is speculated that the perception of stigmatization by others, as measured and tested in the present study, may not be directly relevant to help-seeking for Latin American immigrants. Future research should instead consider testing the effect of Bself-stigma, ${ }^{\wedge}$ which has been defined as a negative perception (e.g., feelings of shame and low self-esteem) that an individual holds towards seeking psychological help (Vogel et al. 2007).

\section{Limitations}

The findings of the current study should be considered with cautions due to several limitations. First, while the TRA model hypothesizes that help-seeking intentions are the best and the most direct predictor of help-seeking behavior, in this study Latin American participants’ Bactual ${ }^{\wedge}$ psychological help-seeking behaviors in the future could not be assessed due to the crosssectional design of the research. Second, even though the re-specified Model 3 in the study was found to fit the data well and seemed conceptually logical, the model was nevertheless statistically derived based on a post-hoc analysis. Thirdly, the proportion of the variance explained by this re-specified model was relatively small (i.e., $\mathrm{R}^{2}=15$ ). This result suggests that there are additional contributing factors to Latin Americans' help-seeking processes that were not accounted for in the current path model. One potential variable of interest is counselor ethnicity, which has been shown to be highly salient for ethnic populations including Latinos (Atkinson and Lowe 1995); that is, adult Latinos might be more amenable to receiving help from counselors of their own ethnicity.

Clearly, future research needs to explore, identify and test other relevant psychosocial and cultural factors that can bear influence on Latin Americans' help-seeking experiences. Finally, the present study mainly focused on the help-seeking experiences of a convenience sample of adult Latin American immigrants residing in the Greater Toronto Area in Canada. Consequently, the generalizability of the study's findings to Latin American immigrants elsewhere cannot be assumed.

\section{Implications for Research and Clinical Practice}

The findings of the present model-testing study of psychological help-seeking among Latin Americans provide a helpful empirical and theoretical basis upon which future scholarly works can build and expand. First of all, future help-seeking research with Latin American populations should consider extending the present investigation by developing a longitudinal study. Such a design would permit researchers to more fully assess the validity of the TRA and monitor the effect of the psychological and cultural antecedents on both help-seeking intentions and behaviors over a period of time. Furthermore, this type of study would also allow researchers to evaluate participants' actual help-seeking behaviors that might evolve and emerge over time. 
Secondly, given the post-hoc nature of the final re-specified model in the study, it is imperative for further research to replicate this model and its various pathways. Kline (2005) stressed that post-hoc models should be carefully replicated using different samples and being compared to other equivalent models. It would, therefore, be highly profitable for future help-seeking research to test the applicability and validity of this model with other, diverse Latin American or racial/ethnic minority sample groups.

Thirdly, the current study demonstrates that both the perceived subjective norms of social referents (i.e., family, parents, siblings) and collective coping based on Latin American cultural values and in-group referencing behaviors are two important antecedents to help-seeking intentions. One possible avenue for future studies is to explore and discern more concisely the exact nature and effect of emotional and structural support from these important referents on the help-seeking process for Latin Americans.

In terms of clinical implications, the results of the study highlight the vital role of familism as a critical cultural value in affecting the help-seeking process of Latin Americans. This observation, coupled with the importance of social referents indicated above, suggests that the decision to seek professional help for Latin Americans is a highly 'social' process-a process that is crucially contingent upon the opinions and expectations of a person's family and social, in-group members and his/her perceived cultural standards. Given that in this study stronger familism was found to relate to more negative help-seeking attitudes, mental health educational and outreach initiatives targeted at Latin American communities should not only attend to attitudes and perceptions of treatment services at the individual level, but also must address negative attitudes and beliefs within the individual's immediately family or social network.

In addition, the present study has implications for multiculturally competent counseling and therapy practice and delivery for Latin American immigrants. As cultural factors (e.g., acculturation, familism, and collective coping) were shown to be important in influencing help-seeking intentions for Latin Americans, it stands to reason that culturally-specific mental health services tailored to Latin Americans may be preferred (Hernandez 2009). To this end, such psychological treatment should involve direct and ongoing consultation with the target Latin American community to which it serves (Hernandez 2009) and actively and intentionally incorporate collective values into such a service (Sue and Sue 2013).

\section{References}

Abraído-Lanza, A. F., Vásquez, E., \& Echeverría, S. E. (2004). En las manos de dios in God’s hands: religious and other forms of coping among Latinos with arthritis. Journal of Consulting and Clinical Psychology, 72(1), 91-102. doi:10.1037/0022-006X.72.1.91.

Ajzen, I. (1991). The theory of planned behavior. Organizational behavior and human decision processes. Special Issue: Theories of Cognitive Self Regulation, 50(2), 179-211. doi:10.1016/0749-5978(91)90020-T.

Ajzen, I., \& Fishbein, M. (1980). Understanding attitudes and predicting social behavior: Illustration of applied social research. Englewood Cliffs: Prentice-Hall.

Altarriba, J., \& Bauer, L. M. (1998). Counseling the Hispanic client: Cuban Americans, Mexican Americans, and Puerto Ricans. Journal of Counseling \& Development, 76(4), 389-396.

Alvidrez, J. (1999). Ethnic variations in mental health attitudes and service use among low-income African American, Latina, and European American young women. Community Mental Health Journal, 35(6), 515530. doi:10.1023/A:1018759201290.

Atkinson, D. R., \& Lowe, S. M. (1995). The role of ethnicity, cultural knowledge, and conventional techniques in counseling and psychotherapy. In J. G. Ponterotto, J. M. Casas, L. A. Suzuki, \& C. M. Alexander (Eds.), Handbook of multicultural counseling (pp. 387-414). Thousand Oaks: Sage.

Brislin, R. W. (1986). The wording and translation of research instruments. In W. J. Lonner \& J. W. Berry (Eds.), Field methods in cross-cultural research (pp. 137-164). Thousand Oaks: Sage. 
Byrne, B. M. (2010). Structural equation modeling with AMOS: Basic concepts, applications and programming (2nd ed.). New York: Taylor and Francis Group.

Cabassa, L. J., \& Zayas, L. H. (2007). Latino immigrants' intentions to seek depression care. American Journal of Orthopsychiatry, 77(2), 231-242. doi:10.1037/0002-9432.77.2.231.

Chiang, L., Hunter, C. D., \& Yeh, C. J. (2004). Coping attitudes, sources, and practices among Black and Latino college students. Adolescence, 39(156), 793-815.

Constantine, M. G., Wilton, L., \& Caldwell, L. D. (2003). The role of social support in moderating the relationship between psychological distress and willingness to seek psychological help among Black and Latino college students. Journal of College Counseling, 6(2), 155-165.

Cramer, K. M. (1999). Psychological antecedents to help-seeking behavior: a reanalysis using path modeling structures. Journal of Counseling Psychology, 46(3), 381-387. doi:10.1037/0022-0167. 46.3.381.

Cuéllar, I., Arnold, B., \& Maldonado, R. (1995). Acculturation rating scale for Mexican Americans-II: a revision of the original ARSMA scale. Hispanic Journal of Behavioral Sciences, 17(3), 275-304. doi:10.1177/ 07399863950173001.

Derogatis, L. R. (2000). Brief symptom inventory 18. Retrieved from http://search.ebscohost.com/login.aspx? direct $=$ true $\& \mathrm{db}=$ loh $\& \mathrm{AN}=15122740 \&$ site $=$ ehost-live.

Fischer, E. H., \& Farina, A. (1995). Attitudes toward seeking professional psychologial help: a shortened form and considerations for research. Journal of College Student Development, 36(4), 368-373.

Garcia, C. (2008). The role of acculturation, mental health beliefs, familism, knowledge of psychotherapy, cultural competency, and ethnic match in attitudes toward seeking psychological help in Latinos. ProQuest Information \& Learning. (Electronic; Print).

Garson, G. D. (2012). Structural equation modeling. Ashboro: Statistical Associates Publishers.

Hernandez, M. (2009). Cultural competence: a literature review and conceptual model for mental health services. Psychiatric Services, 60(8), 1046-1050. doi:10.1176/appi.ps.60.8.1046.

Herrera, R. R. (2006). Acculturation and Chicana/o college students' willingness to seek counseling: Alternative resources and shame as mediating variables. ProQuest Information \& Learning. (Electronic; Print).

Jöreskog, K. G., \& Sörbom, D. (1993). LISREL 8: Structural equation modeling with the SIMPLIS command language. Hillsdale: Lawrence Erlbaum Associates, Inc.

Kim, B. S. K., \& Omizo, M. M. (2003). Asian cultural values, attitudes toward seeking professional psychological help, and willingness to see a counselor. The Counseling Psychologist, 31(3), 343-361. doi:10.1177/ 0011000003031003008

Kim, P. Y., \& Park, I. J. K. (2009). Testing a multiple mediation model of Asian American college students' willingness to see a counselor. Cultural Diversity and Ethnic Minority Psychology, 15(3), 295-302. doi:10. 1037/a0014396.

Kline, R. B. (2005). Principles and practice of structural equation modeling (2nd ed.). New York: Guilford Press.

Kuo, B. C. H. (2011). Culture's consequences on coping: theories, evidences, and dimensionalities. Journal of Cross Cultural Psychology, 42(6), 1084-1100. doi:10.1177/0022022110381126.

Kuo, B. C. H., Kwantes, C. T., Towson, S., \& Nanson, K. M. (2006a). Social beliefs as determinants of attitudes toward seeking professional psychological help among ethnically diverse university students. Canadian Journal of Counselling, 40(4), 224-241.

Kuo, B. C. H., Roysircar, G., \& Newby-Clark, I. R. (2006b). Development of the cross-cultural coping scale: collective, avoidance, and engagement coping. Measurement and Evaluation in Counseling and Development, 39(3), 161-181.

Kuo, B. C. H., Chong, V., \& Joseph, J. (2008). Depression and its psychosocial correlates among older Asian immigrants in North America: a critical review of two decades' research. Journal of Aging and Health, 20, 615-652. doi:10.1177/0898264308321001.

Kuo, B. C. H., Arnold, R., \& Rodriguez-Rubio, B. (2013). Mediating effects of coping in the link between spirituality and psychological distress in a culturally diverse undergraduate sample. Mental Health, Religion and Culture. doi:10.1080/13674676.2013.780015.

Leong, F. T. L., Wagner, N. S., \& Tata, S. P. (1995). Racial and ethnic variations in help-seeking attitudes. In J. G. Ponterotto, J. M. Casas, L. A. Suzuki, \& C. M. Alexander (Eds.), Handbook of multicultural counseling (pp. 415-438). Thousand Oaks: Sage.

Lindsay, C. (2007). Profiles of ethnic communities in Canada: The Latin American community in Canada, 2001 Census. Statistics Canada. Catalogue no. 89-621-XIE-No. 8. Retrieved from http://publications.gc.ca/site/ eng/313856/publication.html. 
Lowinger, R. J. (2012). College students' perceptions of severity and willingness to seek psychological help for drug and alcohol problems. College Student Journal, 46(4), 829-833.

Marín, G., \& Marín, B. V. (1991). Research with Hispanic populations. Thousand Oaks: Sage.

Masuda, A., Anderson, P. L., \& Edmonds, J. (2012). Help-seeking attitudes, mental health stigma, and selfconcealment among African American college students. Journal of Black Studies, 43(7), 773-786.

Miville, M. L., \& Constantine, M. G. (2006). Sociocultural predictors of psychological help-seeking attitudes and behavior among Mexican American college students. Cultural Diversity and Ethnic Minority Psychology, 12(3), 420-432. doi:10.1037/1099-9809.12.3.420.

Moore, J. L., \& Constantine, M. G. (2005). Development and initial validation of the collectivistic coping styles measure with African, Asian, and Latin American international students. Journal of Mental Health Counseling, 27, 329-347.

Prilleltensky, I. (1993). The immigration experience of Latin American families: Research and action on perceived risk and protective factors. Canadian Journal of Community Mental Health, 12(2), 101-116.

Ramos-Sanchez, L., \& Atkinson, D. R. (2009). The relationships between Mexican American acculturation, cultural values, gender, and help-seeking intentions. Journal of Counseling and Development, 87(1), 62-71.

Riano-Alcala, P. (2008). Journeys and landscapes of forced migration: memorializing fear among refugees and internally displaced Colombians. Social Anthropology, 16(1), 1-18. doi:10.1111/j.1469-8676.2008.00036.x.

Robertson, J., \& Fitzgerald, L. F. (1992). Overcoming the masculine mystique: preferences for alternative forms of assistance among men who avoid counseling. Journal of Counseling Psychology, 39(2), 240-246. doi:10. 1037/0022-0167.39.2.240.

Statistics Canada (2007). 2006 Census: Immigration, citizenship, language, mobility and migration. The Daily. Retrieved from http://www.statcan.gc.ca/daily-quotidien/071204/dq071204a-eng.htm.

Steidel, A. G. L., \& Contreras, J. M. (2003). A new familism scale for use with Latino populations. Hispanic Journal of Behavioral Sciences, 25(3), 312-330. doi:10.1177/0739986303256912.

Sue, D. W., \& Sue, D. (2013). Counseling the culturally diverse: Theory and practice (6th ed.). Hoboken: Wiley.

U.S. Department of Health and Human Services (DHHS). (2001). Mental health: Culture, race, and ethnicity- A supplement to mental health: A report of the surgeon general. Rockville, MD: Centre for Mental Health Services. Retrieved from http://mentalhealth.samhsa.gov/cre/default.asp.

Vogel, D. L., Wester, S. R., Wei, M., \& Boysen, G. A. (2005). The role of outcome expectations and attitudes on decisions to seek professional help. Journal of Counseling Psychology, 52(4), 459-470. doi:10.1037/0022-0167.52.4.459.

Vogel, D. L., Wade, N. G., \& Hackler, A. H. (2007). Perceived public stigma and the willingness to seek counseling: the mediating roles of self-stigma and attitudes toward counseling. Journal of Counseling Psychology, 54(1), 40-50. doi:10.1037/0022-0167.54.1.40.

Vogel, D. L., Wade, N. G., \& Ascheman, P. L. (2009). Measuring perceptions of stigmatization by others for seeking psychological help: reliability and validity of a new stigma scale with college students. Journal of Counseling Psychology, 56(2), 301-308. doi:10.1037/a0014903.

Whitley, R., Kirmayer, L. J., \& Groleau, D. (2006). Understanding immigrants' reluctance to use mental health services: a qualitative study from Montreal. The Canadian Journal of Psychiatry/La Revue Canadienne de Psychiatrie, 51(4), 205-209. 